\title{
1 Let's Do the Time Warp Again: Non-linear time series matching as 2 a tool for sequentially structured data in ecology
}

\author{
3 Jens C. Hegg $^{1 *} ;$ Brian P. Kennedy ${ }^{1,2,3}$ \\ 4 \\ $5 \quad{ }^{1}$ Department of Fish \& Wildlife Sciences, University of Idaho, Moscow, ID 83844 \\ $6 \quad{ }^{2}$ Department of Biology, Life Sciences South 252, University of Idaho, Moscow, ID 83844 \\ ${ }^{3}$ Department of Geology, McClure Hall 203, University of Idaho, Moscow, ID 83844
}

\section{Abstract}

Ecological patterns are often fundamentally chronological. However, generalization of

11 data is necessarily accompanied by a loss of detail or resolution. Temporal data in particular

12 contains information not only in data values but in the temporal structure, which is lost when

13 these values are aggregated to provide point estimates. Dynamic Time Warping (DTW) is a time

14 series comparison method that is capable of efficiently comparing series despite temporal offsets

15 that confound other methods. The DTW method is both efficient and remarkably flexible,

16 capable of efficiently matching not only time series but any sequentially structured dataset,

17 which has made it a popular technique in machine learning, artificial intelligence, and big data

18 analytical tasks. DTW is rarely used in ecology despite the ubiquity of temporally structured

19 data. As technological advances have increased the richness of small-scale ecological data, DTW

20 may be an attractive analysis technique because it is able to utilize the additional information

21 contained in the temporal structure of many ecological datasets. In this study we use an example

22 dataset of high-resolution fish movement records obtained from otolith microchemistry to

23 compare traditional analysis techniques with DTW clustering. Our results suggest that DTW is

24 capable of detecting subtle behavioral patterns within otolith datasets which traditional data 
aggregation techniques cannot. These results provide evidence that the DTW method may be useful across many of the temporal data types commonly collected in ecology, as well other sequentially ordered "pseudo time series" data such as classification of species by shape.

Keywords: classification, cluster analysis, data generalization, DTW, dynamic time warping, otolith chemistry, time series

\section{Introduction}

The study of ecology is fundamentally chronological, and the challenges ecologists face with the collection and analysis of their data often reflects this temporal nature (Wolkovich et al. 2014). Populations rise and fall over years. Climate, as well as the rates of predation, parasitism, and competition vary across time, affecting behavior, survival, and reproduction of populations. Analyzing and modeling this data often requires translating data collected at small scales into meaningful metrics that can explain larger phenomenon. This translation, however, inevitably results in loss of information though loss of detail and specificity (Levin 1992). Levin (1992) argues convincingly that simplifying data from the individual to the ecosystem scale should be done with the goal of thoughtfully preserving "minimal sufficient detail" to inform models at larger scales. However, as technology drives increases in the volume and richness of data at the individual and local scale (Hampton et al. 2009, Laurance et al. 2016),

44 it is reasonable to assume that small-scale data may now contain more meaningful data. Analyses

45 that better summarize information-rich data could increase the meaning of aggregated data.

46 Recent advances in time series analysis techniques may be an example of just such a technique

47 (Aghabozorgi et al. 2015). Time series data contains information not just in the values of the 48 data, but in the order of those values (Chatfield 2003, Cressie and Wikle 2011). Many analysis 
techniques collapse these data into discrete time-points, or overall descriptive statistics, in the process removing temporal structure that may be more useful than we realize. New time series

51 analysis tools that have gained prominence in other fields may allow more nuanced treatment of

52 time series data in ecology, decreasing the loss of information in time series data due to 53 aggregation.

One of the most popular time series techniques is Dynamic Time Warping (DTW). DTW

distance is a distance measure (similar to the familiar Euclidian or Mahalanobis distance

measures) which describes the similarity of two time series, or any dataset which can be

expressed sequentially. It was first developed as a method to match sounds in speech recognition,

where the speed and accent of speakers can vary despite the word or phrase being the same,

creating phase shifts that are difficult to match using most distance metrics (Sakoe and Chiba clustering and classification methods (Mueen and Keogh 2016, Sarda-Espinosa 2017).

70 finding the path which matches the most similar points in each series. In the case of two identical

71 time series, the least cost path would be a perfect diagonal. For misaligned series, the algorithm 
72

73

74

matches each point in the two time series with a one-to-many approach, warping the temporal dimension to match the two series (Figure 1B). This warping technique allows time series to be compared after correction for temporal differences that would otherwise skew a Euclidean distance measure.

Despite the increasing popularity of DTW in big-data mining (Keogh and Pazzani 2000, Sakurai et al. 2015), artificial intelligence \& robotics (Xu et al. 2014, Cheng et al. 2015), economics (Lee et al. 2012, Wang et al. 2012), healthcare (Ortiz et al. 2016), and speech recognition (Pi-Yun Chen et al. 2015) these techniques have only been applied in a few cases to ecological data (Debeljak et al. 2010, Cope and Remagnino 2012, Stathopoulos et al. 2014, Tan et al. 2015, Jouary et al. 2016, Baumann et al. 2017, Weideman et al. 2017).

DTW may be useful for many types of ecological data because much of the data that ecologists collect has a temporal component; for example, spatial location data of tagged animals, mark-recapture data, trends in population density, and the timing of spring leaf-out, all are either inherently temporal or could be thought of as a time series. In fact, the use of DTW to analyze "pseudo time series," sequentially ordered data which is not temporal but can be thought of as such for the sake of analysis, has potentially wide application in ecology. Identification of plant or fish species based on shape, or animal movement patterns, are three examples in the literature (Ueno et al. 2006, Cope and Remagnino 2012, Jouary et al. 2016). Even genetics data can be coerced into a time series format for use with time series methods (Rakthanmanon et al. 2012). In many of these cases it is useful to determine the similarity or difference between the structure of data; for example, to classify streams by the characteristics of their hydrograph, or to track the timing of phenological events across decades. Time series clustering tools like DTW provide methods which can efficiently cluster similar time series using all the information 
95 contained in the chronological structure of the data, avoiding some of the problems associated

96 with data aggregation.

97 One example of temporally structured data for which DTW may provide analytical

98 advantages is the life-time chemical records obtained from fish otoliths (or ear stones). Over the

99 same period that time series clustering methods have matured, the microchemical analysis of fish

100 otoliths has taken similarly large strides as an ecological tool, becoming an example of a

101 dramatic increase in data richness at the individual scale (Campana 2005, Secor 2010, Walther

102 2019). With calcium carbonate rings laid down daily, the otolith is a natural temporal record of

103 the environment and life-history of a fish (Campana and Neilson 1985). Otoliths record ambient

104 chemistry which can be used to reconstruct an individual's movements, life-history strategies,

105 and environmental conditions through the life of a fish with remarkable precision (Kennedy et al.

106 1997, 2002, Campana and Thorrold 2001, Hamann and Kennedy 2012, Limburg et al. 2013).

107 Studies now often including multiple chemical and isotopic tracers, each able to reconstruct

108 different multiple facets of a fish's life-history (Walther and Limburg 2012, Hegg et al. 2018).

109 These new techniques create information-rich, time series data of a fish from birth to death

110 (Figure 2A).

111 While the resolution of data extracted from otoliths has increased dramatically, analysis

112 techniques have not taken advantage of the increased information density of high-resolution time

113 series datasets. In most cases data from periods of interest in the fish's life is aggregated, creating

114 a chemical index which can be analyzed as a discrete value, or a vector of values in the

115 multivariate case (Barnett-Johnson et al. 2010, Hegg et al. 2013a, Garcez et al. 2014, Hegg et al.

116 2018). While this is a valid approach, it risks ignoring or obscuring valuable information 
117 contained in the time series structure itself whose shape is affected by growth, movement, and 118 ontogeny.

119 In this paper, we provide an example of how DTW can be used to determine natal origin

120 and life-history from a large dataset of known-origin juvenile Chinook salmon otolith transect

121 data. We demonstrate the ability of DTW to cluster fish using univariate and multivariate

$122{ }^{87} \mathrm{Sr} /{ }^{86} \mathrm{Sr}$ data. Next, we compare these results to a more conventional, model-based discriminate

123 function analysis using aggregated multivariate data, and we demonstrate how the two

124 techniques could be paired to potentially improve location discrimination. We then present the

125 use of nearest-neighbor classification to extend DTW clustering to classify unknown fish.

126 Finally, we discuss the utility of DTW methods in ecology more broadly given our results.

\section{Methods}

\section{Study Species}

Snake River fall Chinook salmon are a threatened population of fall-spawning

130 Oncorhynchus tshawytscha in the Snake River of Idaho, a major tributary to the Columbia River

131 in the northwestern United States (Figure 3). The population is notable for a recent shift in

132 juvenile life-history strategy which recent research suggests is hereditary and an example of

133 contemporary life-history evolution (Williams et al. 2008, Waples et al. 2017). These changes

134 are thought to be driven by anthropogenic changes related to ten hydropower dams which have

135 blocked the majority of historical spawning habitat and created significant changes in the

136 hydrograph and river conditions throughout their current range (Connor et al. 2005, Hegg et al.

137 2013a, Connor et al. 2016). 
The geology of the major spawning tributaries in this watershed is diverse both in age

139

140

141

142 and rock type, creating significant differences in water chemistry between the major spawning areas (Hegg et al. 2013b). Ongoing water sampling throughout the basin has shown that ${ }^{87} \mathrm{Sr} /{ }^{86} \mathrm{Sr}$ signatures in the four main spawning areas of the basin are distinct, and that discriminate

function analysis using ${ }^{87} \mathrm{Sr} /{ }^{86} \mathrm{Sr}$ can be used to determine the locations of juvenile and adult fish using otolith chemistry (Hegg et al. 2013a, 2018).

\section{Otolith Collection and Analysis}

The data used in this study consists of otoliths collected from known-origin, juvenile fall Chinook salmon from throughout their range in the Snake River basin as part of a prior otolith study (Hegg et al. 2018). Juveniles were collected at three locations from 2009 to 2014 ( $\mathrm{n}=376$ ) as part of population surveys conducted across the spawning areas in the Snake, Grande Ronde and Clearwater Rivers by United States Fish and Wildlife Service, Nez Perce Tribe Department of Fisheries Resource Management, and USGS. Samples were also obtained from the two hatcheries producing Fall Chinook in the basin, Lyons Ferry Hatchery and the Nez Perce Tribal Hatchery. Some fish were tagged with passive integrated transponder (PIT) tags and released, then recaptured weeks later when their tag was detected at Lower Granite Dam, the first dam fish encounter on their path downstream.

Otolith samples were collected and processed using established procedures for otolith analysis (Secor et al. 1992, Hegg et al. 2013a). Detailed methods for this dataset, including laser ablation and ICP-MS information, are available in Hegg et al. (2018) . Continuous chemical transects from the core (birth) to the edge (death) were collected from each otolith, creating a sequential chemical record throughout the life of the fish (Figure $2 \mathrm{~A}$ and $\mathrm{B}$ ). This was done using using a New Wave UP-213 laser ablation sampling system. This system was coupled with 
161 a Thermo Scientific Neptune multi-collector inductively coupled plasma mass-spectrometer

162 (ICP-MS) for ${ }^{87} \mathrm{Sr} /{ }^{86} \mathrm{Sr}$ ratio. The ablation system was coupled with a Thermo Scientific

163 Element2 ICP-MS to measure elemental concentrations of calcium $\left({ }^{43} \mathrm{Ca}\right)$, strontium $\left({ }^{86} \mathrm{Sr}\right)$, 164 barium $\left({ }^{138} \mathrm{Ba}\right)$, Magnesium $\left({ }^{25} \mathrm{Mg}\right)$, and Manganese $\left({ }^{55} \mathrm{Mn}\right)$. Elemental measurements were 165 calculated as ratios to calcium and expressed as $\mathrm{mm} / \mathrm{mol}$ following Hegg et al. (2018).

\section{Multivariate Discriminate Function Classification}

A model-based discriminant function was created to classify fish to known location. The goal was to develop a robust classification which could than later be applied to unknown adult

169 fish to inform ecology and management of the population.

Within our dataset, juveniles were assigned to a known origin based on the location of

171 capture. Juveniles which were captured and sacrificed during beach seine sampling were

172 assigned to the river reach in which they were captured; the Upper Snake River (USK), the

173 Lower Snake River (USK), the Clearwater River (CWS), or the Grande Ronde River (GR). Fish

174 that were PIT tagged and recaptured at Lower Granite Dam were assigned a second known

175 location in Lower Granite Reservoir (LGR). Therefore, it was possible for a fish to have both a

176 known natal location and a known downstream location. Some fish were caught in the dam

177 forebay as a part of prior studies and their natal location was not known, although their migration

178 timing suggested Clearwater River origin. These fish were assigned only a known downstream

179 location of LGR. Juveniles obtained from Lyons Ferry Hatchery (LFH) and Nez Perce Tribal

180 Hatchery (NPTH) were assigned to these natal locations respectively.

181 We defined the natal signature as the average of the chemistry between $300 \mu \mathrm{m}$ and

$182400 \mu \mathrm{m}$ from the core of the otolith, creating a five-element vector of chemical signatures for

183 each fish. This was based on prior research showing this to be the beginning of stable juvenile 
184 signatures (Hegg et al. 2018). Fish arriving at Lower Granite Dam can be moving downstream

185 quickly and may have only recently equilibrated. Therefore, we averaged the signatures from

186 only the outer $50 \mu \mathrm{m}$ from the edge to obtain the downstream signature. Fish captured at LGR

187 with a ${ }^{87} \mathrm{Sr} /{ }^{86} \mathrm{Sr}$ signature far removed from that of LGR were assumed to be fast moving

188 migrants, fish moving too fast to have equilibrated to the surrounding water. These were

189 removed to maintain a consistent training set for the discriminant function.

190 Classifying fish to location was done using a model-based discriminant function using

$191{ }^{87} \mathrm{Sr} /{ }^{86} \mathrm{Sr}, \mathrm{Sr} / \mathrm{Ca}, \mathrm{Ba} / \mathrm{Ca}, \mathrm{Mn} / \mathrm{Ca}$, and $\mathrm{Mg} / \mathrm{Ca}$ as independent variables and known location as the

192 classifier. We used the \{mclust\} package (version 5.2) for R to build a model based discriminant

193 function (Fraley and Raftery 2007, Scrucca et al. 2016). The dataset was randomly split into a

194 training set (80\%) and test set (20\%), with the training-set used to construct the discriminate

195 function. Related river reaches were combined successively until an acceptable misclassification

196 rate was achieved. The final discriminate function was then applied to the test-set to quantify its

197 performance on unknown data.

\section{Dynamic Time Warping Cluster Analysis}

Time series clustering using DTW distance was used to identify groups of similar fish

200 based on the shape of their otolith transects. The DTW algorithm is extremely sensitive to

201 variation in mean, requiring all time series to be normalized (Keogh and Kasetty 2002,

202 Rakthanmanon et al. 2012). In the case of fish life-history transects this normalization can be

203 problematic, as the absolute mean of the ${ }^{87} \mathrm{Sr} /{ }^{86} \mathrm{Sr}$ ratio is meaningful as a marker of fish location,

204 and once normalized to a mean of zero and unit variance it is possible for the shape of two

205 otolith transects from different rivers to look alike, and thus cluster together despite being

206 meaningfully different. 
To remove the location ambiguity created by z-normalization we used a two-step

clustering process to partition the transects by mean, and then sub-cluster by DTW distance. The

mean of each ${ }^{87} \mathrm{Sr} /{ }^{86} \mathrm{Sr}$ transect was calculated, means data was scaled, then clustered using

210 model-based clustering in the Mclust package for R. Initial clustering was performed with the

211 intention of finding the minimum number of clusters which cleanly separated the known groups.

212 The clusters obtained from Mclust where then sub-clustered using DTW distance on both

213 univariate ${ }^{87} \mathrm{Sr} /{ }^{86} \mathrm{Sr}$ and multivariate data including the elemental ratios used in the discriminate

214 function classification above.

Prior to DTW clustering, a centered, 60-point, rolling average was used to smooth

${ }^{87} \mathrm{Sr} /{ }^{86} \mathrm{Sr}$ transects. A 10-point rolling average was used to smooth elemental data, as the longer

217 integration time during collection of this data results in smoother data. Transects were then re-

218 interpolated to a length of 200 cells, which allows faster calculation through the implementation

219 of lower bounds without a loss of the ability to accurately match time series (Ratanamahatana

220 and Keogh 2004, Al-Naymat et al. 2009). This length was used as a rounded approximation of

221 the mean length of series in the dataset. The mean length of transects was 173 cells, with a

222 maximum length of 422, a minimum of 61 and a standard deviation of 61 cells. A comparison of

223 selected data before and after interpolation is included in Appendix A.

224 Clustering was performed on the univariate and multivariate transects using the

225 \{dtwclust package (Sarda-Espinosa 2017) using agglomerative hierarchical clustering \{hclust\}

226 method in $\mathrm{R}$ with Wards distance. A 5\% Sakoe-Chiba window was employed to decrease

227 processing effort and limit potentially erroneous warping (Sakoe and Chiba 1978,

228 Ratanamahatana and Keogh 2004, Al-Naymat et al. 2009). The Sakoe-Chiba window limits the 
229

230

amount of deviation from the diagonal when determining the warping path between two time series (Figure 1B). Otolith transects were z-normalized prior to analysis.

Clustering was exploratory, with a goal to cut the dendrogram of each group at a location which minimized the number of clusters while maintaining clusters which were easily interpretable based on the known-origin of the fish within each cluster. Window size was varied from $1 \%$ to $100 \%$ after the optimal number of groups was found to determine if adjusting the Sakoe-Chiba window (Sakoe and Chiba 1978) affected the stability of the results.

The same clustering approach was repeated for univariate data using the Euclidian distance measure. This was done to test whether DTW was a superior distance metric over the more traditional Euclidean distance which does not take into account temporal warping.

Euclidian distance was not performed on the multivariate data as there are no packages which implement multivariate Euclidean distance for time series clustering.

\section{Combining DTW with Discriminate Function Analysis}

In one case the discriminant function was unable to separate two groups of fish from known locations, the USK and LSK, allowing us to test the ability of DTW to separate these indistinguishable groups. We applied hierarchical clustering to the training set data from these confounded groups, reserving the test-set data to test the robustness of the grouping using nearest-neighbor classification. For the clustering step we used a 5\% Sakoe-Chiba window and Keogh lower bounds. The effect of window size was tested qualitatively by varying the window from $1 \%$ to $100 \%$ to test the stability of the clustering results. We cut the dendrogram to create three clusters based on the results of the overall DTW clustering. We then used this cluster solution to predict the cluster membership of the test-set otoliths from these confounded groups using 1-nearest-neighbor classification, to test the stability of these cluster results to unknown 
data. Comparison to known water chemistry from Hegg et al. (2018) was used to evaluate the veracity of this group membership.

\section{Results}

\section{Multivariate Discriminate Function Analysis}

Initial data exploration indicated that the LGR group, as expected, contained a number of

juvenile fish whose signatures had not equilibrated and instead reflected signatures of upstream

River and later at LGR which exhibited a very high, Clearwater River signature. These fish were removed to provide a robust training set, under the assumption that adult fish would exhibit a

261 clear signature in these locations, having had time to chemically equilibrate.

Additionally, a group of anomalous life-history transects were identified in the CWS

263 group which did not appear to conform to the known signatures which a Clearwater origin fish

264 would experience, nor did they match the expected patterns or signatures seen in NPTH fish. All

265 of these fish were captured late in the year and could potentially be unmarked hatchery juveniles,

266 erroneously identified Spring Chinook from upriver populations, or an unknown source. To

267 avoid biasing our CWS training set these fish were excluded $(n=25)$.

269 groups. Many LSK fish appeared, subjectively, to have originated in the USK and moved very

270 early to the LSK downstream. Evidence of this type of early movement has been observed in the 271 population (Ken Tiffan, USGS, unpublished data). However, without evidence to clearly identify

272 these potentially early-moving juveniles they were kept within their known-origin groupings. 
Model based clustering resulted in a model with variable, ellipsoidal and diagonal variance structures for each group. The initial classification attempt resulted in large misclassification errors between the LSK and USK groups. The USK and LSK groups were

276 subsequently combined and the classification was run again. This final training set classification 277 resulted in an absolute training error of $3.6 \%(n=298)$, with a 10 -fold cross-validation error rate 278 of $12.8 \%(\mathrm{SE}=3.3 \%)$. Classification of the test set $(\mathrm{n}=74)$ resulted in an overall classification 279 error rate of $12.2 \%$. (Table 1$)$

\section{Dynamic Time Warping Cluster Analysis} defined groupings in the dendrogram which largely corresponded to the three major river systems in the basin (Table 2). The first cluster was made up largely of transects from the

284 Clearwater River ( $\mathrm{n}=101)$ with high mean ${ }^{87} \mathrm{Sr} /{ }^{86} \mathrm{Sr}$ and is referred to as the Clearwater cluster.

285 Seventeen samples in this group were from other locations, the majority of which were of unknown origin. The second cluster, the Snake River cluster, was a mixed cluster made up of

fish from the Upper and Lower Snake Rivers, NPTH and LFH hatcheries with intermediate mean

${ }^{87} \mathrm{Sr} /{ }^{86} \mathrm{Sr}$ transects, The third group was made up entirely of fish from the Grande Ronde River

289 with low ${ }^{87} \mathrm{Sr} /{ }^{86} \mathrm{Sr}$ values. Clearwater cluster separated into three clusters (Figure 4A, Table 2). The first cluster was made up of 83 fish with a steeply ascending ${ }^{87} \mathrm{Sr} /{ }^{86} \mathrm{Sr}$ profile consistent with the transition from

294 maternal otolith signature to that of the Clearwater River. The second cluster separated 16 of the 295 fish which were omitted from the discriminate function in the section above due to their 
anomalous signature. The third cluster consisted of fish with an ${ }^{87} \mathrm{Sr} /{ }^{86} \mathrm{Sr}$ transect that quickly ascended toward the Clearwater and then descended toward the lower signature of the Snake River. The majority of cluster 3 fish were of unknown origin and captured in Lower Granite Reservoir. The remaining fish in cluster 3 exhibited a range of unique patterns. 1 containing only a single sample with an anomalous, increasing ${ }^{87} \mathrm{Sr} /{ }^{86} \mathrm{Sr}$ transect (Figure 4B, Table 2). The second cluster contained the remainder of the samples, all of which exhibited a steeply declining ${ }^{87} \mathrm{Sr} /{ }^{86} \mathrm{Sr}$ signature followed by a small increase at the end of the transect. Univariate DTW sub-clustering of the Snake River cluster resulted in four distinct clusters (Figure 4C, Table 2). Subjectively cluster 1 contained fish with a signature beginning near the global marine signature $(0.70918)$ and increasing toward the signature of the USK. This cluster was composed of a majority of fish from NPTH (16) and fish from the LSK which were subsequently captured in LGR (9). Cluster 2 appeared more mixed, with a combination of increasing signatures similar to cluster 1 and a large number of invariant signatures from LFH.

310 The majority of cluster 2 fish were from LFH (18) but large numbers of fish from other locations

311 as well, including LSK (13), NPTH (13), and LSK fish captured in LGR (11). Cluster 3 transects

312 appeared to be dominated by a signature decreasing from the global marine signature toward the

313 USK signature and was dominated by fish from USK (29). This cluster also included a large

314 number of fish captured in the LSK reach (22). Cluster 4 appeared to separate a ${ }^{87} \mathrm{Sr} /{ }^{86} \mathrm{Sr}$

315 signature decreasing from the global marine signature before rising and crossing the global

316 marine signature to end at the signature of the USK or LGR. The majority of fish in cluster 4

317 were of USK origin, later captured in LGR (17) with a smaller number originating in the LSK 318 (10). 
Overall, the univariate DTW clustering results showed some ability to classify fish, though clusters were not unambiguous. Particularly in the Clearwater River, DTW was able to

321 separate fish which had already been identified as having an anomalous signature (Cluster 2),

322 and to distinguish fish with a likely origin in the Clearwater which were captured further

323 downstream in LGR. Sub-clustering of the Snake River cluster showed some ability to separate

324 hatchery fish (Clusters 1 and 2), and some ability to distinguish patterns in the ${ }^{87} \mathrm{Sr} /{ }^{86} \mathrm{Sr}$ transects

325 which could distinguish fish originating in the USK and LSK despite their later downstream

326 movement which confounded the discriminate function. Varying the size of the Sakoe-Chiba

327 window had very little impact on the DTW results.

Univariate sub-clustering of ${ }^{87} \mathrm{Sr} /{ }^{86} \mathrm{Sr}$ transects using Euclidean distance resulted in very

329 similar clustering results and dendrograms to the DTW results. The most significant difference

330 between the two distance metrics was the ordering of sub-clusters in the Clearwater River. The

331 details of these results are not presented to avoid repetition.

\section{Multivariate DTW Sub-clustering}

Multivariate, hierarchical DTW sub-clustering resulted in more straightforward sub-

334 clustering results. Multivariate clustering excluded $\mathrm{Mg} / \mathrm{Ca}$ ratio as a variable. This was done

335 after determining that outliers within the $\mathrm{Mg} / \mathrm{Ca}$ transects resulted in poor clustering results

336 overall. The interpretability of clustering results improved markedly after removal of $\mathrm{Mg} / \mathrm{Ca}$

337 from the dataset.

338 Within the Clearwater River cluster, DTW identified four distinct cluster groups (Figure

339 5A, Table 3). Cluster 1 was made up of a majority of fish of unknown natal origin captured in

340 LGR (12) with a single fish from the CW group. Cluster 2 was made up of CW origin fish (20)

341 with a sharply ascending ${ }^{87} \mathrm{Sr} /{ }^{86} \mathrm{Sr}$ transect similar to Clearwater sub-cluster 1 in the univariate 
case. Cluster 3 was made up of 15 samples with the anomalous transect shape which was origin NPTH fish in cluster 2. Alternatively, the possibility of an unknown source cannot be eliminated.

Sub-cluster 4 in the Clearwater River cluster contained fish predominantly of CW origin, with 2 fish of unknown natal origin, one fish of unknown origin captured in LGR, and 1 with ascending pattern as Cluster 2. However, they were distinguished by an ascending pattern in reasons for the differences in the shape of the elemental ratio transects are unknown, but it is

357 possible that this represents a meaningful difference in life-history despite the similarity in ${ }^{87} \mathrm{Sr} /{ }^{86} \mathrm{Sr}$ profile. Sub-clustering of the Grande Ronde cluster using DTW resulted in three clusters.

360 Clustering height was an order of magnitude lower than for the other groups, indicating that 361 clusters were more closely related (Figure 5B). Sub-clusters 1 and 3 displayed very similar $362{ }^{87} \mathrm{Sr} /{ }^{86} \mathrm{Sr}$ transects but were distinguished by increasing $\mathrm{Ba} / \mathrm{Ca}$ and $\mathrm{Mn} / \mathrm{Ca}$ in sub-cluster 1 and a 363 peak in $\mathrm{Ba} / \mathrm{Ca}$ and $\mathrm{Mn} / \mathrm{Ca}$ midway through the transect for Cluster 3. Cluster 2 was made up of a 364 single fish which displayed a unique upward trending ${ }^{87} \mathrm{Sr} /{ }^{86} \mathrm{Sr}$ signature but similar elemental 
ratio patterns to sub-cluster 3. All of the fish in the Grande Ronde clusters were captured in the GR (Table 3).

Sub-clustering of the samples from the Snake River cluster using multivariate DTW resulted in 6 well-defined clusters. Cluster 1 displayed a descending pattern of ${ }^{87} \mathrm{Sr} /{ }^{86} \mathrm{Sr}$ ratios beginning near the global marine signature and declining toward the ${ }^{87} \mathrm{Sr} /{ }^{86} \mathrm{Sr}$ signature of the Upper Snake river before rising slightly toward the global marine signature near the end of the transect (Figure 5C). Elemental ratios showed an increasing trend in $\mathrm{Ba} / \mathrm{Ca}$ and $\mathrm{Mg} / \mathrm{Ca}$, with a decreasing trend in $\mathrm{Sr} / \mathrm{Ca}$. The cluster contained a majority of fish with natal origins in LSK, with 38 captured in LSK and an additional 10 initially captured in LSK before being recaptured downstream in LGR. Fish from the USK made up the remainder of the known origin fish in this sub-cluster, with 24 captured in the USK and 6 initially captured in the USK before being recaptured in LGR.

Snake River sub clusters 2 and 3 were comprised almost entirely of fish captured at each of the two hatcheries in the study (Figure 5C). Snake River sub-cluster 2 showed a largely flat ${ }^{87} \mathrm{Sr} /{ }^{86} \mathrm{Sr}$ transect and highly variable elemental ratios. It was made up of 26 fish from LFH, comprising all of the fish from this hatchery included in the study. A single fish from NPTH was also included in this cluster. Sub-cluster 3 was similarly made up of hatchery origin fish, with 24 fish from NPTH comprising the only members of the group. Snake River sub-clusters 4 and 5 were comprised mostly of downstream migrants captured in the LSK and USK respectively, later re-captured at LGR (Figure 5C, Table 3). Subcluster 4 was dominated by fish originating in LSK before being recaptured at LGR (15). The ${ }^{87} \mathrm{Sr} /{ }^{86} \mathrm{Sr}$ transects followed a pattern originating near the global marine signature and increasing toward the signature of the LSK river. $\mathrm{Ba} / \mathrm{Ca}$ transects showed an increasing pattern, $\mathrm{Mn} / \mathrm{Ca}$ 
exhibited a peak at 150 cells in the re-interpolated data, and $\mathrm{Sr} / \mathrm{Ca}$ showed an increasing pattern with a peak near the end of the transect. In contrast sub-cluster 5 was made up largely of fish originating in USK before being recaptured in LGR (22). This group displayed a pattern of ${ }^{87} \mathrm{Sr} /{ }^{86} \mathrm{Sr}$ ratios decreasing below the global marine signature, toward the signature of the USK,

392 before rising toward the LSK signature at the end of the transect. Elemental ratios in this group 393 showed similar patterns to sub-cluster 4 in $\mathrm{Mn} / \mathrm{Ca}$ but decreasing $\mathrm{Sr} / \mathrm{Ca}$ and a late peak in $\mathrm{Ba} / \mathrm{Ca}$. Snake River sub-cluster 6 contained a majority of fish captured in LSK (18), with fish

395 from LSK captured in LGR (4), USK captured in LGR (3), and NPTH (3) (Table 3). This group 396 displayed an ${ }^{87} \mathrm{Sr} /{ }^{86} \mathrm{Sr}$ transect increasing from the global marine signature toward the LSK 397 signature, with $\mathrm{Ba} / \mathrm{Ca}$ and $\mathrm{Mn} / \mathrm{Ca}$ increasing across the transect and $\mathrm{Sr} / \mathrm{Ca}$ decreasing (Figure 398 5C). life histories, while also identifying additional life-histories within the data which other methods

401 did not. Within the Clearwater River DTW sub-cluster 1 contains fish captured at LGR with 402 unknown natal-origin. The change from an increasing ${ }^{87} \mathrm{Sr} /{ }^{86} \mathrm{Sr}$ pattern consistent with the $\mathrm{CW}$ 403 early in life, to a lower LGR signature later in life is evident (Figure 5A). These unknown- origin 404 fish were collected by USGS in 2012 in the forbay of Lower Granite dam and the collection 405 notes include, "Unknown origin. Likely from Clearwater but could be hatchery or natural," based 406 on the expected timing of outmigration from the Clearwater River. This provides evidence that 407 the DTW algorithm is able to successfully match these fish to their natal location, despite the 408 change in transect shape caused by movement into the lower ${ }^{87} \mathrm{Sr} /{ }^{86} \mathrm{Sr}$ signature of LGR. Further, 409 three of these fish demonstrate movement into LGR at a much earlier point than the others 
410 (Figure 5A), yet the time-warping nature of DTW and the similarity of their elemental ratios

411 allows them to be clustered together.

413 USK and LSK fish are confounded due to early movement (Figure 5C). Each of these clusters

$414{ }^{87} \mathrm{Sr} /{ }^{86} \mathrm{Sr}$ transects originate near the global marine signature in the maternally influenced region

415 of the otolith $(\sim 0-150 \mu \mathrm{m}$, Hegg et al. 2018). Transects them toward either the signature of the

416 USK which is below the global marine signature (sub-cluster 1 and 5) or the USK and LGR

417 which is largely above the global marine signature (clusters 4 and 6) during the natal period

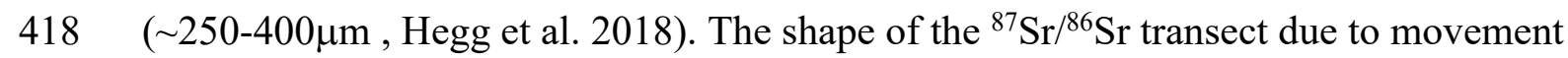

419 downstream to LGR is clearly visible in cluster 5, and the addition of elemental transects clearly

420 delineates this cluster from a similar ${ }^{87} \mathrm{Sr} /{ }^{86} \mathrm{Sr}$ shape for fish originating in the LSK (cluster 4 and

421 6). Sub-cluster 1, however, contains a majority of fish whose transects clearly end within a

422 signature lower than the global marine signature which should indicate an origin in the USK.

423 Despite this the majority of fish in this sub-cluster were captured in LSK. This indicates that

424 these fish likely originated in the USK, moved downstream to the LSK, and were captured

425 before their signatures had equilibrated to the LSK signature.

\section{Combining DTW with Discriminate Function Analysis}

428 discriminate function training-set was done to test the ability of DTW to separate the confounded 429 group. This clustering of the confounded USK/LSK group resulted in three clear clusters (Figure

$4306 \mathrm{~A}$ and $\mathrm{B})$. The first cluster contained fish originating in LSK (83\%) with a shape similar to

431 cluster 6 in the multivariate sub-clustering above. The second cluster contained a mixture of fish 432 captured in the LSK (51\%) and USK (45\%), but with an ${ }^{87} \mathrm{Sr} /{ }^{86} \mathrm{Sr}$ shape similar to Snake River 
multivariate sub-cluster 1 above. The third cluster contained downstream migrants recaptured in

434 LGR after being initially captured in the USK (44\%) and LSK (41\%) before being recaptured in

435 LGR. The dendrogram did not provide simple separation of this downstream migrant group into

436 LSK-LGR and USK-LGR clusters. This result indicated the ability of DTW to separate LSK fish

437 from USK fish, as well as fish from each natal region captured downstream at LGR, based on

438 the different transect shape produced in each natal river. Sakoe-Chiba window width did not

439 have a large effect on clustering results.

Testing this classification using 1-nearest neighbor to assign group membership resulted

441 in the majority of the test set being assigned to the second cluster (Figure 6C and D). Cluster one

442 contained three fish, one captured in LSK and two downstream migrants captured in LSK and

443 USK respectively and recaptured in LGR. Cluster 2 contained nine fish captured in LSK, three

444 downstream migrants originating in LSK and recaptured in LGR, one fish captured in USK, and

445 one downstream migrant from USK captured in LGR. Cluster 3 was made up entirely of

446 downstream migrants with three fish originating in LSK and five originating in USK before

447 being captured in LGR.

Comparison of the cluster transects to the range of water ${ }^{87} \mathrm{Sr} /{ }^{86} \mathrm{Sr}$ signatures collected

449 from the USK and LSK reaches supports the contention that clusters 1 and 2 separate fish by

450 their true natal river reach (Figure 6). Cluster 1 mostly contains fish with a ${ }^{87} \mathrm{Sr} /{ }^{86} \mathrm{Sr}$ signature

451 reflective of the LSK in the natal region between $\sim 250 \mu \mathrm{m}-450 \mu \mathrm{m}$ from the otolith core in both

452 the training and test set, and most were captured in the LSK reach (Figure 6) Cluster 2 shows a

453 signature below the global marine value, reflective of the USK reach water samples, during the

454 natal period $(\sim 250 \mu \mathrm{m}-450 \mu \mathrm{m})$. This cluster is split between fish captured in the USK and LSK,

455 despite the samples having a consistent shape. This similarity in transect shape provides 
456 additional evidence that early downstream movement is confounding the ${ }^{87} \mathrm{Sr} /{ }^{86} \mathrm{Sr}$ signatures of

457 juveniles captured in the LSK reach. Cluster 3 is made up of a mix of fish from both LSK and

458 USK natal origins which subsequently display an increasing signature consistent with the LSK

459 water samples prior to capture, consistent with their known downstream migration.

The test-set results indicate that the clusters are robust to transect shape, with test-set

461 transects largely mirroring the ${ }^{87} \mathrm{Sr} /{ }^{86} \mathrm{Sr}$ transect shapes from the training set. Few test-set fish

462 were assigned to cluster 1, making evaluation difficult. Cluster 2 appeared to robustly contain

463 fish with a transect shape indicating USK natal origin. Cluster 3 again contained only

464 downstream migrants captured in LGR, indicating that this cluster was robust in identifying the

465 downstream migrant life-history.

\section{Discussion}

Finding analytical methods that best "extract and abstract those fine-scale features that

468 have relevance...in other scales," is particularly important in ecology (Levin 1992). Our results

469 indicate that DTW clustering, leveraging the structured nature of time series data, can distinguish

470 important groupings in otolith life-history data. The ability of DTW to efficiently use the

471 additional richness in time series datasets, in effect extracting important fine scale features

472 without aggregation data loss, may be useful for a variety of other ecological datasets as well.

473 DTW was very sensitive to life-history differences recorded in otolith transects.

474 Univariate ${ }^{87} \mathrm{Sr} /{ }^{86} \mathrm{Sr}$ data was capable of classifying fish to location in ways broadly comparable

475 to the traditional discriminant function technique using multivariate chemical signatures. Further,

476 DTW identified additional life-history patterns that were not apparent in the multivariate

477 discriminate function. The classification of two clearly different life-histories within the 
478 Clearwater River group, including a life-history which were subjectively identified as different

479 and held out of the discriminate functions analysis, was particularly interesting (Cluster 2, Figure

480 4A). This indicates that the use of otolith transect shape may provide a more robust, data-

481 centered, method to identify outlying groups rather than simply relying on expert opinion.

However, univariate DTW clustering was largely unable to reliably distinguish hatchery

483 fish in the Snake River group, mixing NPTH samples with LSK samples due to a similarity in

484 shape, and clustering LFH fish throughout the remaining clusters (Figure 4C). Further, univariate

485 DTW clustering did not perform differently than clustering based on Euclidian distance, which is

486 somewhat surprising. The outmigration timing of juvenile Fall Chinook varies significantly both

487 year-to-year and between individuals within a natal reach (Connor et al. 2005, 2013, Tiffan and

488 Connor 2012). This variation in timing would be expected to negatively affect the Euclidean

489 distance measure. Standardizing the length of each time series and clustering first on the mean

490 may have improved the similarity in shape, or temporal warping may be low enough to make

491 Euclidean distance a viable measure in this population. However, in more complex matching

492 tasks where much more variation and complexity is the norm, such as otolith data of adult fish or

493 searching for specific movements within a larger otolith transect, it is likely that the temporal

494 flexibility of DTW would be superior.

495 Multivariate DTW clustering was much more successful and sensitive in classifying fish

496 life-history. In the Snake River group multivariate DTW was able to cluster hatchery fish from

497 NPTH and LFH with a high degree of precision (Clusters 2 and 3, Figure 5C). Further, despite

498 the confounding effect of downstream movement DTW appeared to separate fish by USK and

499 LSK natal origin with a high degree of specificity to transect shape (Clusters 1 and 4, Figure 5C).

500 Further, DTW was able to distinguish downstream movement from each of these natal locations 
into LGR and cluster them separately based largely on differences on differences in the shape of trace-element transects between the upper river and LGR (Clusters 5 and 6, Figure 5C). interesting. Both in the Clearwater and the Grande Ronde groups DTW identified clusters which otherwise similar downstream movement patterns. 
identified as LSK when, in fact, they are recent migrants from the USK reach whose chemistry uncover meaningful associations in the data that traditional methods cannot. 
or specific patterns of phenology across years or across a landscape. This "open-ended" method has been used successfully in several examples of extremely large datasets (Tormene et al. 2009, Rakthanmanon et al. 2012). The method is also easily applied to data that is not strictly temporal but can be sequentially ordered, for species identification by shape or identification of movement

551 patterns (Ueno et al. 2006, Cope and Remagnino 2012, Jouary et al. 2016). Also, where good

552 training data exist DTW combined with nearest-neighbor classification has been shown to be a

553 robust and accurate classification method (Kate 2015). Further, DTW can be applied to

554 multivariate time series, though careful pre-processing is required (Mueen and Keogh 2016).

556 has not embraced the technique. These methods are increasingly easy to utilize, with DTW

557 packages available in multiple popular platforms including R, Python, Java and SAS (Leonard

558 and Wolfe 2001, Salvador and Chan 2007, Albanese and Visintainer 2012, Gulzar 2015).

559 Analysis of ecological data is always a balance between detail and parsimony, and often

560 temporal in nature. DTW provides an additional tool for ecologists to maximize the information

561 available to answer ecological questions by taking advantage of the information contained in 562 sequentially structured data.

\section{Acknowledgements}

566 for their insights into the early drafts. In particular, E. Benson and J. Reader deserve credit for

567 prepping a large number of juvenile otoliths for this project. Thanks to the lab undergraduates;

568 A. Miera, J. Greenwood, K. Wilcox, and B. Carman for their help with data post-processing.

569 Thanks also to L. Rayala for early editing. 
bioRxiv preprint doi: https://doi.org/10.1101/2021.04.19.440490; this version posted April 20, 2021. The copyright holder for this preprint (which was not certified by peer review) is the author/funder, who has granted bioRxiv a license to display the preprint in perpetuity. It is made available under aCC-BY-NC-ND 4.0 International license. 
bioRxiv preprint doi: https://doi.org/10.1101/2021.04.19.440490; this version posted April 20, 2021. The copyright holder for this preprint (which

was not certified by peer review) is the author/funder, who has granted bioRxiv a license to display the preprint in perpetuity. It is made available under aCC-BY-NC-ND 4.0 International license.

\section{$571 \quad$ Tables}

572

Table 1 - Classification accuracy of discriminate function training set

573

574

\begin{tabular}{|c|c|c|c|c|c|c|}
\hline & \multicolumn{6}{|c|}{ Observed } \\
\hline & CWS & CRB & LFH & LGR & NPTH & USK/LSK \\
\hline CWS & 64 & 0 & 0 & 0 & 0 & 0 \\
\hline CRB & 0 & 21 & 0 & 0 & 0 & 0 \\
\hline $\mathrm{LFH}$ & 0 & 0 & 19 & 0 & 2 & 0 \\
\hline LGR & 2 & 0 & 0 & 60 & 0 & 9 \\
\hline NPTH & 2 & 0 & 2 & 0 & 21 & 5 \\
\hline USK & 0 & 0 & 0 & 2 & 1 & 92 \\
\hline
\end{tabular}


Table 2 - Results of two-level clustering of known-origin juvenile fish using univariate DTW distance. Fish were first clustered by the mean $87 \mathrm{Sr} / 86 \mathrm{Sr}$ of the entire transect using k-means, resulting in three broad clusters corresponding to the river of origin (Clearwater River, Snake River, and Grande Ronde River). These clusters were sub-clustered using hierarchical clustering and dynamic time warping distance on the $87 \mathrm{Sr} / 86 \mathrm{Sr}$ transect for each otolith. Sample size in each sub-cluster is shown, with the percentage of each known-origin group shown in parentheses.

Clusters of Transect Mean

\begin{tabular}{|c|c|c|c|c|c|c|c|c|c|}
\hline \multirow[b]{3}{*}{ DTW sub-cluster } & \multicolumn{9}{|c|}{ Clusters of Transect Mean } \\
\hline & \multicolumn{3}{|c|}{ Clearwater $\mathbf{R}$. } & \multicolumn{4}{|c|}{ Snake R. } & \multicolumn{2}{|c|}{ Grande RondesB } \\
\hline & 1 & 2 & 3 & 1 & 2 & 3 & 4 & 1 & 2584 \\
\hline $\mathbf{C W}$ & $\begin{array}{c}79 \\
(78.2 \%)\end{array}$ & $\begin{array}{c}16 \\
(15.8 \%)\end{array}$ & $6(5.9 \%)$ & - & - & - & - & - & $\begin{array}{r}585 \\
-586\end{array}$ \\
\hline LSK & ( & - & - & $\begin{array}{c}7 \\
(11.9 \%)\end{array}$ & $\begin{array}{c}13 \\
(22.0 \%)\end{array}$ & $\begin{array}{c}29 \\
(49.2 \%)\end{array}$ & $\begin{array}{c}10 \\
(16.9 \%)\end{array}$ & - & $\begin{array}{r}587 \\
-588 \\
580\end{array}$ \\
\hline LSK $\rightarrow$ LGR & - & - & $1(2.9 \%)$ & $\begin{array}{c}9 \\
(26.5 \%)\end{array}$ & $\begin{array}{c}11 \\
(32.4 \%)\end{array}$ & $\begin{array}{c}8 \\
(23.5 \%)\end{array}$ & $\begin{array}{c}5 \\
(14.7 \%)\end{array}$ & - & $\begin{array}{r}589 \\
-590\end{array}$ \\
\hline USK & - & - & - & - & $\begin{array}{c}5 \\
(17.2 \%)\end{array}$ & $\begin{array}{c}22 \\
(75.9 \%)\end{array}$ & $2(6.9 \%)$ & - & $\begin{array}{r}591 \\
-592\end{array}$ \\
\hline USK $\rightarrow$ LGR & - & - & - & $\begin{array}{c}5 \\
(15.2 \%)\end{array}$ & - & $\begin{array}{c}11 \\
(33.3 \%)\end{array}$ & $\begin{array}{c}17 \\
(51.5 \%)\end{array}$ & - & $\begin{array}{r}593 \\
-594 \\
505\end{array}$ \\
\hline LFH & - & - & - & - & $\begin{array}{c}18 \\
(69.2 \%)\end{array}$ & $\begin{array}{c}5 \\
(19.2 \%)\end{array}$ & $\begin{array}{c}3 \\
(11.5 \%)\end{array}$ & - & $\begin{array}{l}595 \\
-596\end{array}$ \\
\hline NPTH & - & $1(3.2 \%)$ & - & $\begin{array}{c}16 \\
(51.6 \%)\end{array}$ & $\begin{array}{c}13 \\
(41.9 \%)\end{array}$ & - & $1(3.2 \%)$ & - & $\begin{array}{r}597 \\
-598 \\
500\end{array}$ \\
\hline Unknown & $\begin{array}{c}1 \\
(25.0 \%)\end{array}$ & - & - & - & $\begin{array}{c}2 \\
(50.0 \%)\end{array}$ & - & $\begin{array}{c}1 \\
(25.0 \%)\end{array}$ & - & $\begin{array}{r}599 \\
-600\end{array}$ \\
\hline Unknown $\rightarrow$ LGR & $3(8.8 \%)$ & $2(5.9 \%)$ & $\begin{array}{c}9 \\
(26.5 \%)\end{array}$ & $\begin{array}{c}6 \\
(17.6 \%\end{array}$ & $\begin{array}{c}8 \\
(23.5 \%)\end{array}$ & $2(5.9 \%)$ & $\begin{array}{c}4 \\
(11.8 \%)\end{array}$ & - & $\begin{array}{r}601 \\
-602 \\
603\end{array}$ \\
\hline GR & - & - & - & - & - & - & - & $1(4.0 \%)$ & $\begin{array}{r}24 \\
(96.804 \\
605\end{array}$ \\
\hline
\end{tabular}


Table 3 - Results of two-level clustering of known-origin juvenile fish using multivariate DTW distance. Fish were first clustered by the mean $87 \mathrm{Sr} / 86 \mathrm{Sr}$ of the entire transect using k-means, resulting in three broad clusters corresponding to the river of origin (Clearwater River, Snake River, and Grande Ronde River). These clusters were sub-clustered using hierarchical clustering and multivariate dynamic time warping distance of $87 \mathrm{Sr} / 86 \mathrm{Sr}, \mathrm{Sr} / \mathrm{Ca}, \mathrm{Ba} / \mathrm{Ca}$, and $\mathrm{Mn} / \mathrm{Ca}$ signatures on the transect across each otolith.

\begin{tabular}{|c|c|c|c|c|c|c|c|c|c|c|c|c|c|}
\hline \multirow[b]{3}{*}{ DTW sub-cluster } & \multicolumn{13}{|c|}{ Clusters of Transect Mean } \\
\hline & \multicolumn{4}{|c|}{ Clearwater $\mathbf{R}$. } & \multicolumn{6}{|c|}{ Snake R. } & \multicolumn{3}{|c|}{ Grande Ronde R. } \\
\hline & 1 & 2 & 3 & 4 & 1 & 2 & 3 & 4 & 5 & 6 & & 1 & 2 \\
\hline CW & $\begin{array}{c}1 \\
(1.0 \%)\end{array}$ & $\begin{array}{c}20 \\
(19.8 \%)\end{array}$ & $\begin{array}{c}15 \\
(14.9 \%)\end{array}$ & $\begin{array}{c}65 \\
(64.4 \%)\end{array}$ & & - & - & - & - & - & - & - & - \\
\hline LSK & - & - & - & - & $\begin{array}{c}38 \\
(64.4 \\
\%)\end{array}$ & - & - & $\begin{array}{c}2 \\
(3.4 \%)\end{array}$ & $\begin{array}{c}1 \\
(1.7 \%)\end{array}$ & $\begin{array}{c}18 \\
(30.5 \%)\end{array}$ & - & - & - \\
\hline LSK $\rightarrow$ LGR & - & - & - & $\begin{array}{c}1 \\
(2.9 \%)\end{array}$ & $\begin{array}{c}10 \\
(29.4 \\
\%)\end{array}$ & - & - & $\begin{array}{c}15 \\
(44.1 \%)\end{array}$ & $\begin{array}{c}4 \\
11.8 \%)\end{array}$ & $\begin{array}{c}4 \\
(11.8 \%)\end{array}$ & - & - & - \\
\hline USK & - & - & - & - & $\begin{array}{c}24 \\
(82.8 \\
\%)\end{array}$ & - & - & $\begin{array}{c}5 \\
(17.2 \%)\end{array}$ & - & - & - & - & - \\
\hline USK $\rightarrow$ LGR & - & - & - & - & $\begin{array}{c}6 \\
(18.2 \\
\%)\end{array}$ & - & - & $\begin{array}{c}2 \\
(6.1 \%)\end{array}$ & $\begin{array}{c}22 \\
(66.7 \%)\end{array}$ & $\begin{array}{c}3 \\
(9.1 \%)\end{array}$ & - & - & - \\
\hline LFH & - & - & - & - & & $\begin{array}{c}26 \\
(100 \%)\end{array}$ & & - & - & - & - & - & - \\
\hline NPTH & - & - & $\begin{array}{c}1 \\
(3.2 \%)\end{array}$ & - & & $\begin{array}{c}1 \\
(3.2 \%)\end{array}$ & $\begin{array}{c}24 \\
(77.4 \%)\end{array}$ & $\begin{array}{c}2 \\
(6.5 \%)\end{array}$ & - & $\begin{array}{c}3 \\
(9.7 \%)\end{array}$ & - & - & - \\
\hline Unknown & - & - & - & $\begin{array}{c}1 \\
(35 . \%)\end{array}$ & & - & - & $\begin{array}{c}1 \\
(25.0 \%)\end{array}$ & $\begin{array}{c}1 \\
(25.0 \%)\end{array}$ & $\begin{array}{c}1 \\
(25.0 \%)\end{array}$ & - & - & - \\
\hline Unknown $\rightarrow$ LGR & $\begin{array}{c}12 \\
(35.3 \%)\end{array}$ & - & - & $\begin{array}{c}2 \\
(5.9 \%)\end{array}$ & $\begin{array}{c}1 \\
(2.9 \%)\end{array}$ & - & - & $\begin{array}{c}10 \\
(29.4 \%)\end{array}$ & $\begin{array}{c}6 \\
17.6 \%)\end{array}$ & $\begin{array}{c}3 \\
(8.8 \%)\end{array}$ & - & - & - \\
\hline GR & - & - & - & - & & - & - & - & - & - & $\begin{array}{c}15 \\
(60.0 \%)\end{array}$ & $\begin{array}{c}1 \\
(4 \%)\end{array}$ & $\begin{array}{c}9 \\
(36.0 \%)\end{array}$ \\
\hline
\end{tabular}




\section{Figures}
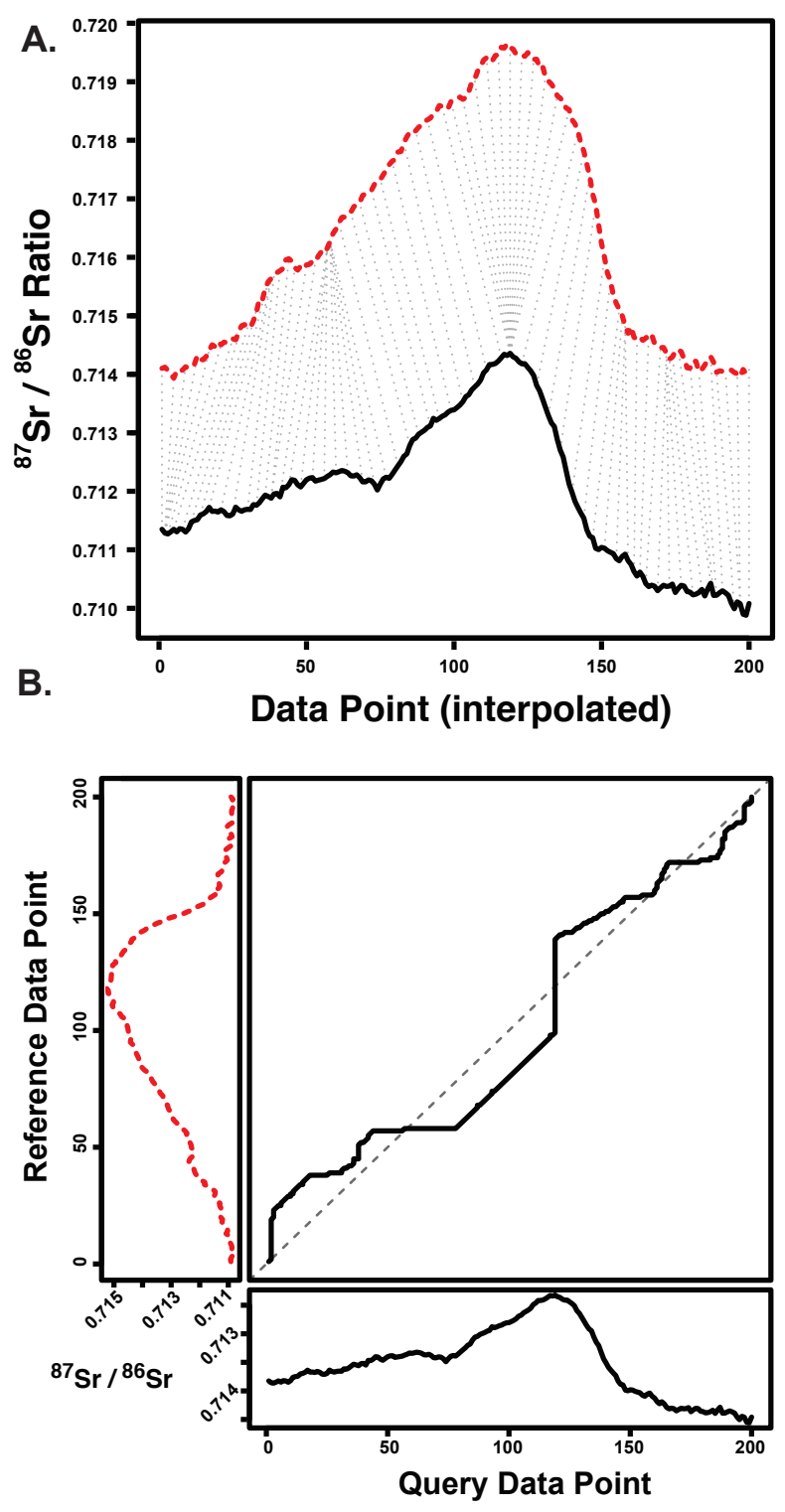

Figure 1 - Two otolith ${ }^{87} \mathrm{Sr} /{ }^{86} \mathrm{Sr}$ transects of two fish caught in the LGR reach of the Snake River are shown. Dynamic Time Warping computes the amount of warping on the temporal ( $\mathrm{x}$ ) axis needed to optimally align two series (A). Dotted grey lines show matching points along these series computed by DTW (a subsample of matching points is shown and transects are offset by 0.004 to improve clarity). The optimal warping path (B) is shown between the two time series. Transects are re-interpolated to 200 cells but were not z-normalized prior to 


\section{A.}
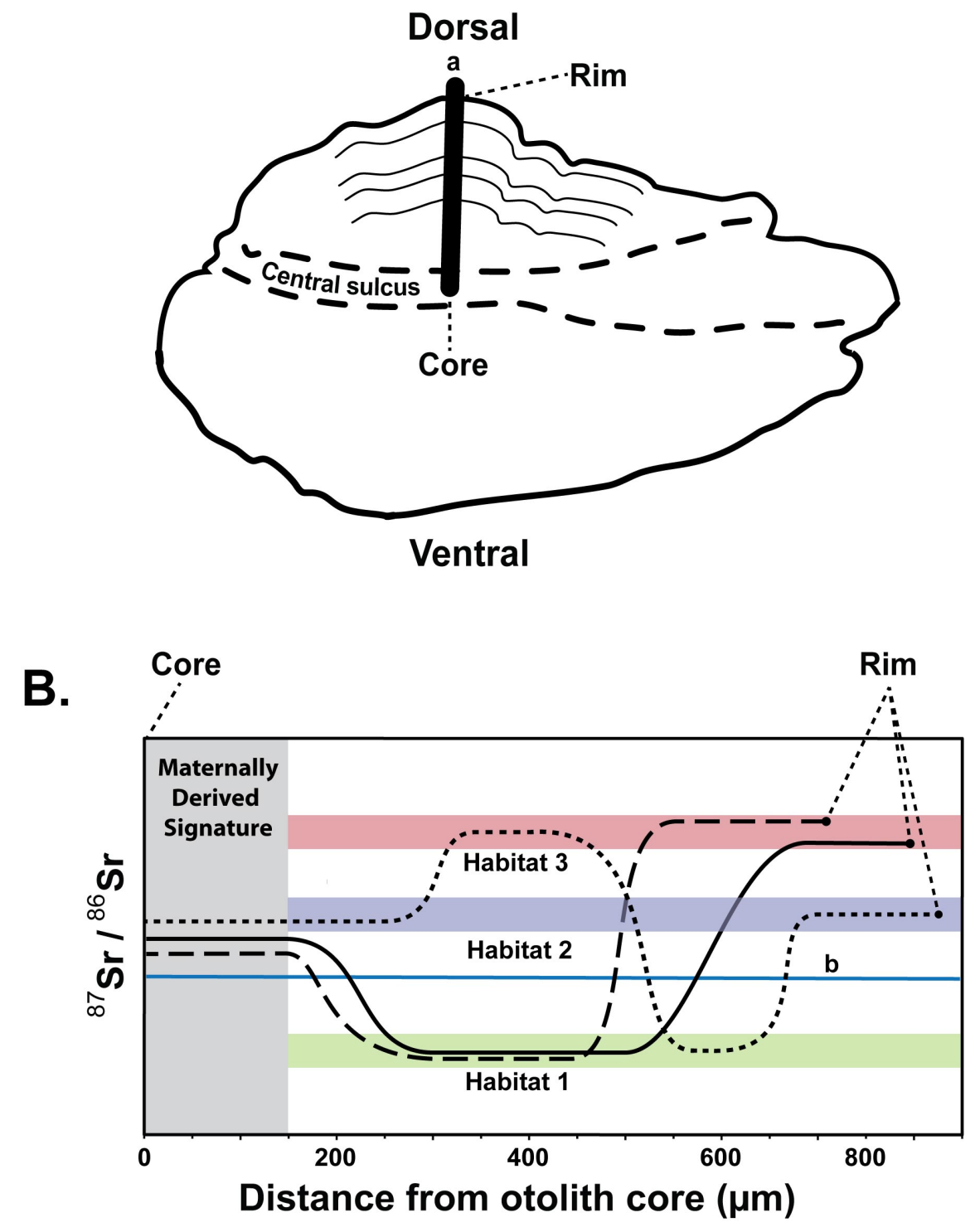

Figure 2 - Otoliths (A) are laser ablated on a path $90^{\circ}$ from the sulcus (a). This analysis creates a temporally structured dataset for each fish, representing the chemistry of the rivers they inhabited throughout their life. These otolith chemical transects (B) are represented with microns from the core of the otolith on the temporal (x) axis. Movement timing, growth and location combine to form the shape of the ${ }^{87} \mathrm{Sr}{ }^{86} \mathrm{Sr}$ curve as a fish moves through different habitats. Otolith ${ }^{87} \mathrm{Sr} /{ }^{86} \mathrm{Sr}$ transects for to hypothetical fish inhabiting the same two habitats, habitats 1 and 3 , are shown (solid and heavy dashed black lines). The otolith transects for these fish which experienced the same habitats are phase-shifted on the temporal axis, a condition which is not controlled in Euclidean distance time series matching. the flexible temporal dimension in the DTW method allows for matching these transects while distinguishing other life-history shapes 


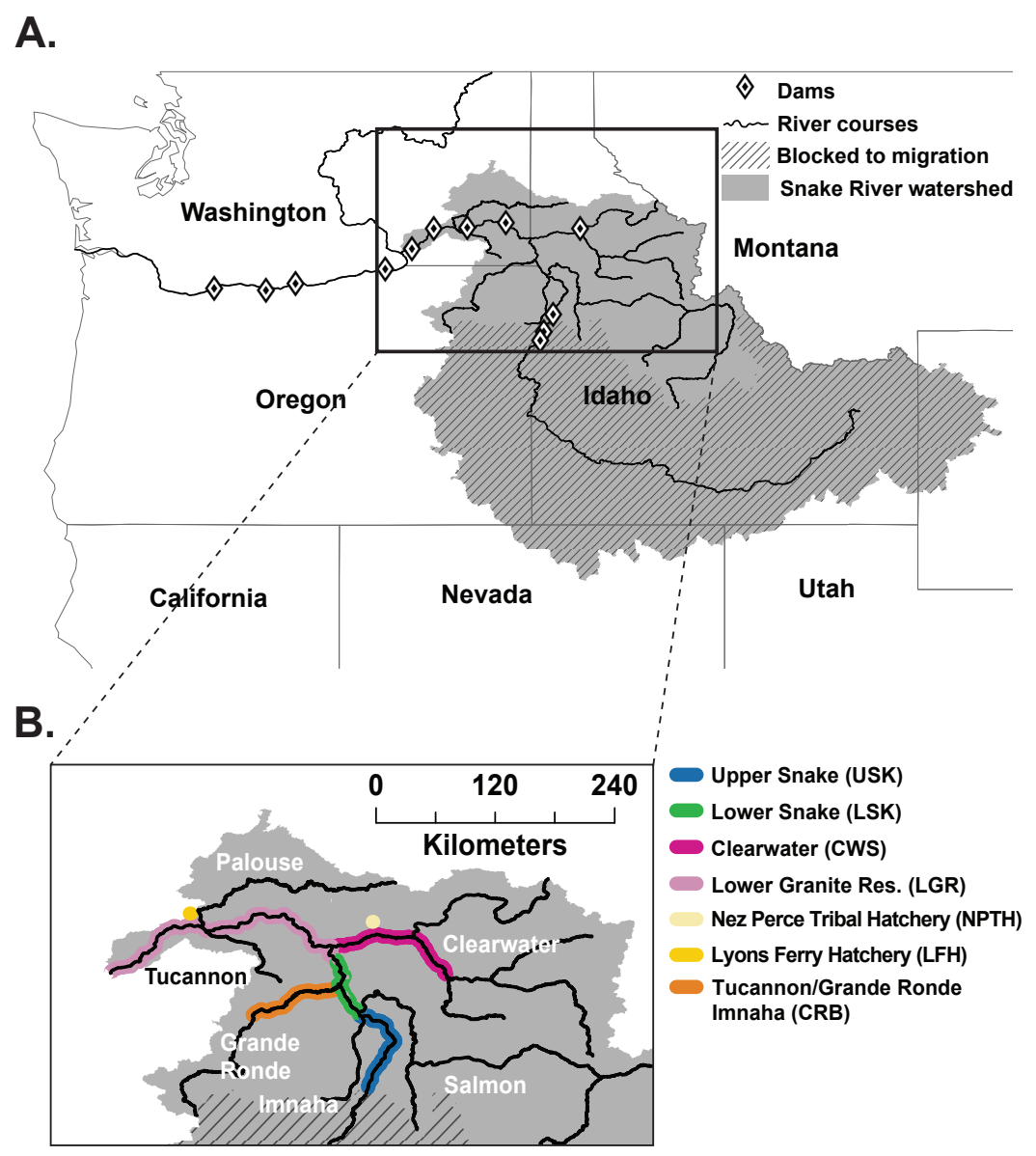

Figure 3 - Snake River fall Chinook salmon inhabit the Snake River (a) in the US States of Idaho, Washington and Oregon. The extent of spawning for known origin fish in our study (b) is highlighted. The location of the two hatcheries in the basin are noted with colored dots. The Tucannon, Grande Ronde, and Salmon Rivers were not sampled for juveniles and produce a very small percentage of the wild fish in the basin. 
A
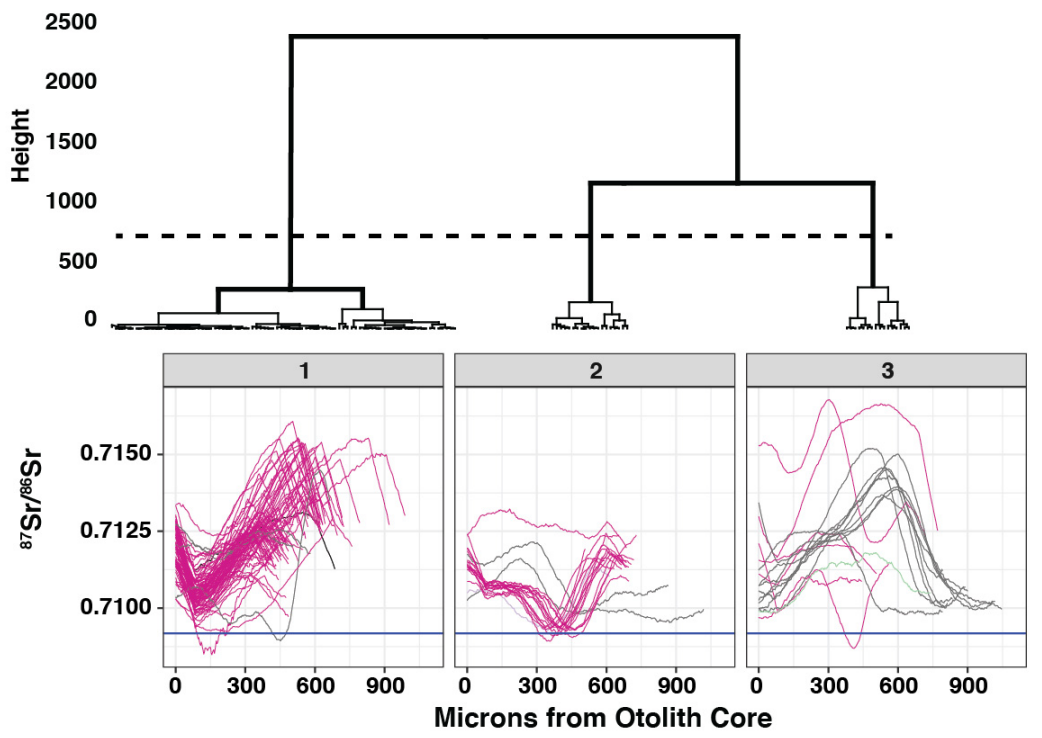

6000

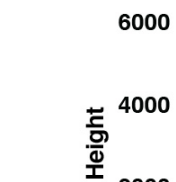

C

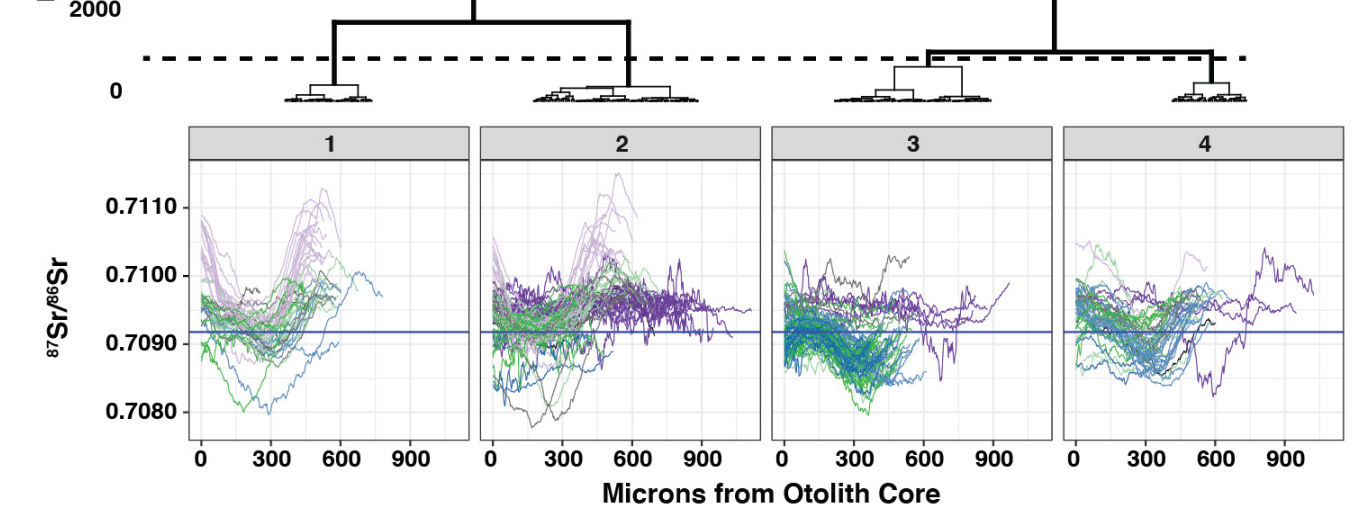

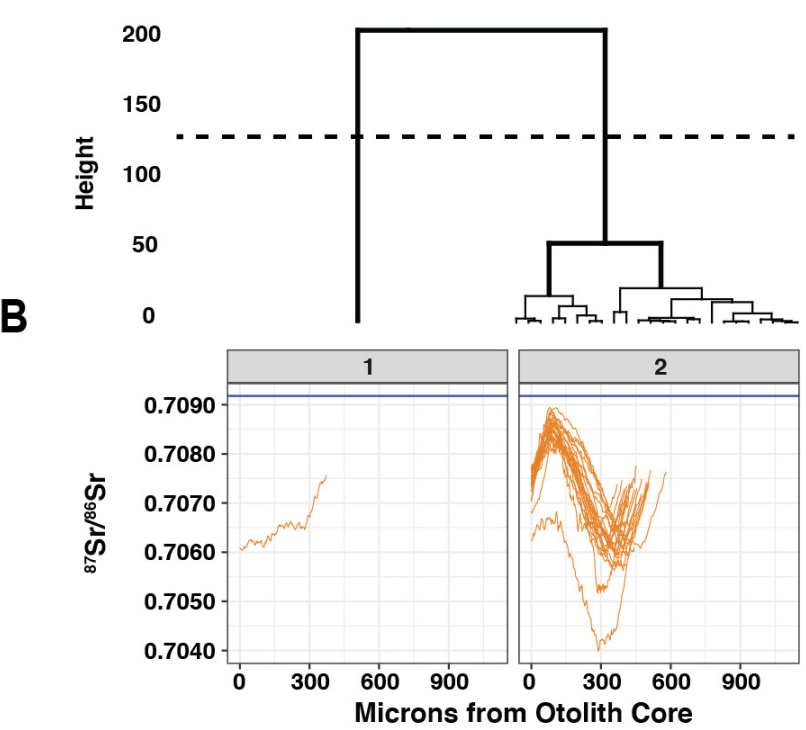

\section{Location}

Natal $\rightarrow$ Downstream

CW

LSK

LSK $\longrightarrow$ LGR

USK

USK $\longrightarrow$ LGR

LFH

NPTH

Unknown

Unknown $\rightarrow$ LGR

GR 
Figure 4 - Univariate hierarchical DTW sub-clustering of juvenile fish ${ }^{87} \mathrm{Sr} /{ }^{86} \mathrm{Sr}$ transects are shown. Panels A through C represent the sub-clustering for each cluster based on overall transect mean. Dashed lines show the height the dendrogram was cut to determine the cluster solution. Transects are colored by the known location of the fish. Some fish were captured in their natal location, released, and recaptured downstream in LGR. The blue horizontal line represents the global marine value of ${ }^{87} \mathrm{Sr} /{ }^{86} \mathrm{Sr}(0.70918)$ for reference. 

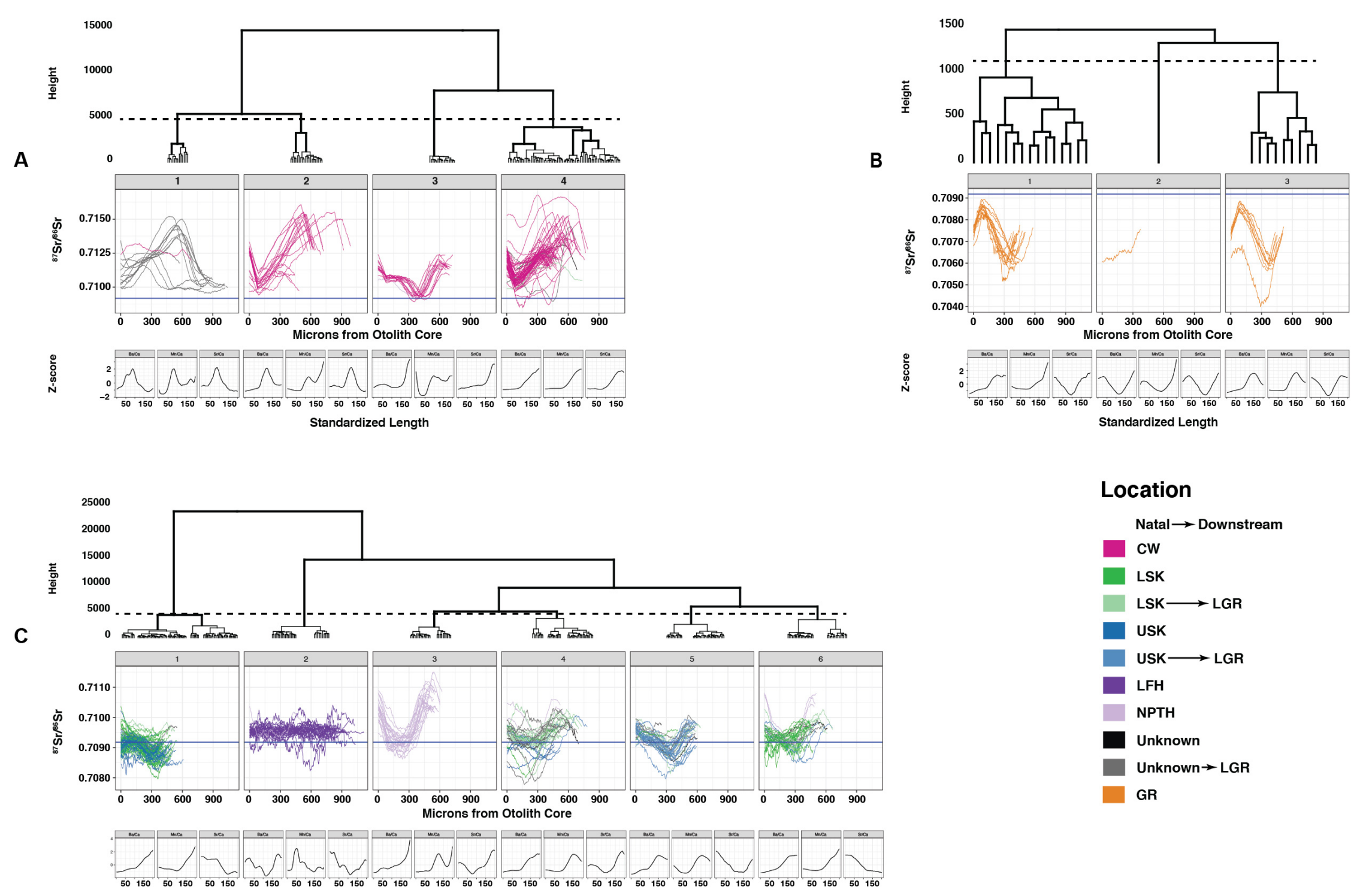

\section{Location}

Natal $\rightarrow$ Downstream
cW
LSK
LSK $\longrightarrow$ LGR
USK
USK $\longrightarrow$ LGR
LFH
NPTH
Unknown
Unknown $\rightarrow$ LGR
GR


Figure 5 - Multivariate, hierarchical DTW sub-clustering of juvenile fish using ${ }^{87} \mathrm{Sr} /{ }^{86} \mathrm{Sr}, \mathrm{Sr} / \mathrm{Ca}, \mathrm{Ba} / \mathrm{Ca}$, and $\mathrm{Mn} / \mathrm{Ca}$ transects are shown. Panels A through $\mathrm{C}$ represent the sub-clustering for each cluster based on overall transect mean. Dashed lines show the location the dendrogram was cut to determine the cluster solution. Transects are colored by the known location of the fish. Some fish were captured in their natal location, released, and recaptured downstream in LGR. Small panels below each cluster show the znormalized centroid for each trace-element in each cluster. The blue horizontal line represents the global marine value of ${ }^{87} \mathrm{Sr} /{ }^{86} \mathrm{Sr}$ $(0.70918)$ for reference. 
A

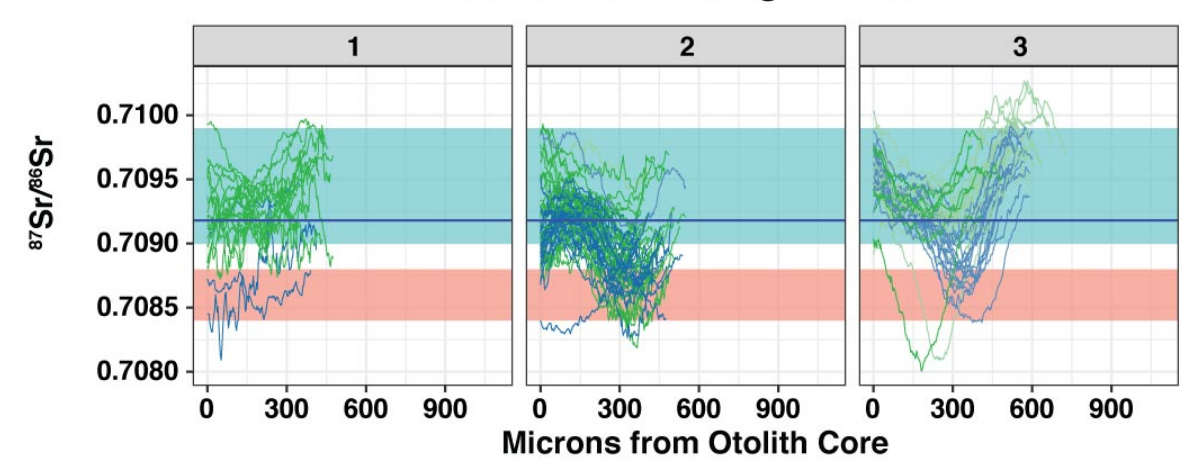

C

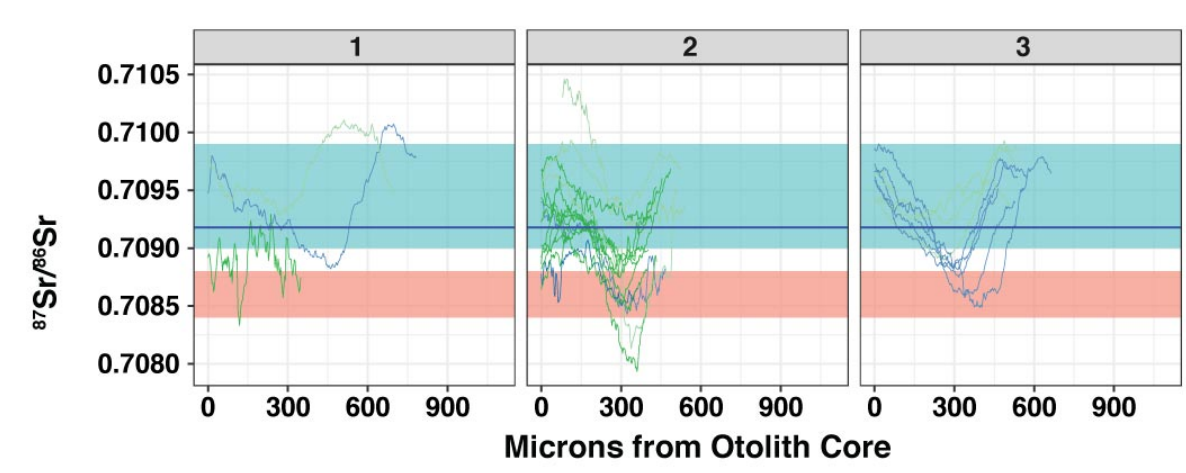

B
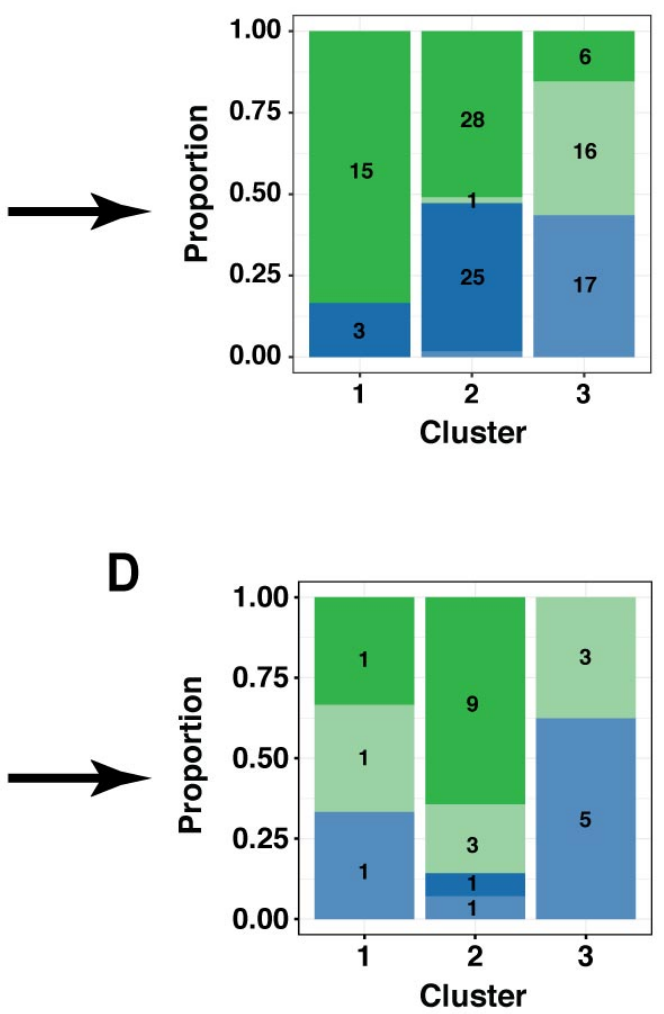

\section{Location}

Natal $\rightarrow$ Downstream

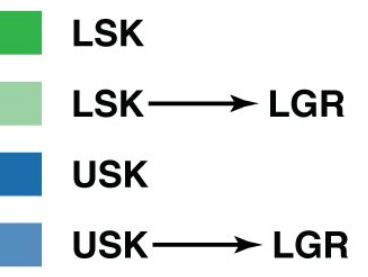

\section{${ }^{87} \mathrm{Sr} /{ }^{87} \mathrm{Sr}$ Water Samples}

\section{Upper Snake River}

Lower Snake River/Lower Granite Res. 
2 Figure 6 - Multivariate, hierarchical DTW clustering of juvenile fish in the confounded USK/LSK group from the discriminate 3 function are shown. Clustering was performed on ${ }^{87} \mathrm{Sr} /{ }^{86} \mathrm{Sr}, \mathrm{Sr} / \mathrm{Ca}, \mathrm{Ba} / \mathrm{Ca}$, and $\mathrm{Mn} / \mathrm{Ca}$ transects. Panel A shows the clustering of fish in 4 the discriminate function training set. The proportion of fish in each training-set cluster is shown in Panel B, with the number of fish 5 in each cluster shown within the colored region of the plot. Panel $\mathrm{C}$ shows the clustering of fish in the test set. The proportion of fish 6 in each test-set cluster is shown in Panel B, with the number of fish in each cluster shown within the colored region of the plot. Fish 7 transects are colored by their location of capture. Some fish were captured, released, and subsequently re-captured downstream in the 8 LGR. Colored rectangles show the range of water samples collected over a longterm study of the Snake River spawning areas (Hegg 9 et al. 2013a, 2018). The blue horizontal line represents the global marine value of ${ }^{87} \mathrm{Sr} /{ }^{86} \mathrm{Sr}(0.70918)$ for reference. 


\section{References Cited}

Aghabozorgi, S., A. Seyed Shirkhorshidi, and T. Ying Wah. 2015. Time-series clustering - A decade review. Information Systems 53:16-38.

Al-Naymat, G., S. Chawla, and J. Taheri. 2009. SparseDTW: A novel approach to speed up dynamic time warping. Conferences in Research and Practice in Information Technology Series 101:117-127.

Albanese, D., and R. Visintainer. 2012. mlpy: Machine Learning Python. arXiv:1-4.

Barnett-Johnson, R., D. J. Teel, and E. Casillas. 2010. Genetic and otolith isotopic markers identify salmon populations in the Columbia River at broad and fine geographic scales. Environmental biology of fishes 89:533-546.

Baumann, M., M. Ozdogan, A. D. Richardson, and V. C. Radeloff. 2017. Phenology from Landsat when data is scarce: Using MODIS and Dynamic Time-Warping to combine multiyear Landsat imagery to derive annual phenology curves. International Journal of Applied Earth Observation and Geoinformation 54:72-83.

Campana, S. 1999. Chemistry and composition of fish otoliths: pathways, mechanisms and applications. Marine Ecology Progress Series 188:263-297.

Campana, S. E. 2005. Otolith science entering the 21st century. Marine and Freshwater Research $56: 485-496$.

Campana, S. E., and S. R. Thorrold. 2001. Otoliths, increments, and elements: keys to a comprehensive understanding of fish populations? Canadian Journal of Fisheries and Aquatic Sciences 58:30-38.

Campana, S., and J. Neilson. 1985. Microstructure of fish otoliths. Canadian Journal of Fisheries and Aquatic Sciences 42:1014-1032.

Chatfield, C. 2003. The Analysis of Time Series: An Introduction. 6th edition. Taylor \& Francis, Boca Raton, FL.

Cheng, H., Z. Dai, Z. Liu, and Y. Zhao. 2015. An image-to-class dynamic time warping approach for both 3D static and trajectory hand gesture recognition. Pattern Recognition 55:137-147.

Connor, W. P., B. D. Arnsberg, J. A. Chandler, T. D. Cooney, P. A. Groves, J. A. Hesse, G. W. 
Mendel, D. J. Milks, D. W. Rondorf, S. J. Rosenberger, M. L. Schuck, K. F. Tiffan, R. S. Waples, and W. Young. 2016. A Retrospective ( circa 1800-2015) on the Abundance, Spatial Distribution, and Management of Snake River Basin Fall Chinook. Portland, OR.

Connor, W. P., J. G. Sneva, K. F. Tiffan, R. K. Steinhorst, and D. Ross. 2005. Two alternative juvenile life history types for fall Chinook salmon in the Snake River basin. Transactions of

Connor, W. P., K. F. Tiffan, J. M. Plumb, and C. M. Moffitt. 2013. Evidence for Density-

Cope, J., and P. Remagnino. 2012. Classifying Plant Leaves from Their Margins Using Dynamic Springer, Berlin, Heidelberg.

Cressie, N., and C. K. Wikle. 2011. Statistics for Spatio-Temporal Data. Page Wiley Series on Probability and Statistics. First edition. John Wiley \& Sons, Inc., Hoboken, NJ.

Debeljak, M., G. R. Squire, D. Kocev, C. Hawes, M. W. Young, and S. Džeroski. 2010. Analysis of time series data on agroecosystem vegetation using predictive clustering trees. Ecological Modelling 222:2524-2529.

Fraley, C., and A. E. Raftery. 2007. Bayesian regularization for normal mixture estimation and model-based clustering. Journal of Classification 24:155-181.

Garcez, R. C. S., R. Humston, D. Harbor, and C. E. C. Freitas. 2014. Otolith geochemistry in young-of-the-year peacock bass Cichla temensis for investigating natal dispersal in the Rio Negro (Amazon - Brazil) river system. Ecology of Freshwater Fish:n/a-n/a.

Gulzar, H. M. 2015, June 15. Comprehensive Python module for computing and visualizing dynamic time warping alignment: DTWPy. University of Stavanger, Norway.

Hamann, E. J., and B. P. Kennedy. 2012. Juvenile dispersal affects straying behaviors of adults in a migratory population. Ecology 93:733-740.

Hampton, S. E., C. A. Strasser, J. J. Tewksbury, W. K. Gram, A. E. Budden, A. L. Batcheller, C. S. Duke, and J. H. Porter. 2009. Big data and the future of ecology Data-intensive Science: A New Paradigm for Biodiversity Studies. bioscience 11:156-162.

31 Hegg, J. C., B. P. Kennedy, and P. M. Chittaro. 2018. What did you say about my mother? The 
complexities of maternally derived chemical signatures in otoliths. Canadian Journal of Fisheries and Aquatic Sciences 14:1-14.

Hegg, J. C., B. P. Kennedy, P. M. Chittaro, and R. W. Zabel. 2013a. Spatial structuring of an evolving life-history strategy under altered environmental conditions. Oecologia 172:10171029.

Hegg, J. C., B. P. Kennedy, and A. K. Fremier. 2013b. Predicting strontium isotope variation and

Jouary, A., G. Sumbre, E. Normale, and S. Erieure. 2016. Automatic classification of behavior in

Kate, R. J. 2015. Using dynamic time warping distances as features for improved time series classification. Data Mining and Knowledge Discovery 30:283-312.

Kennedy, B. P., C. L. Folt, J. D. Blum, and C. P. Chamberlain. 1997. Natural isotope markers in salmon. Nature 387:766-767.

Kennedy, B. P., A. Klaue, J. D. Blum, C. L. Folt, and K. H. Nislow. 2002. Reconstructing the lives of fish using Sr isotopes in otoliths. Canadian Journal of Fisheries and Aquatic Sciences 59:925-929.

Keogh, E., and S. Kasetty. 2002. On the Need for Time Series Data Mining Benchmarks: A

Keogh, E. J., and M. J. Pazzani. 2000. Scaling up dynamic time warping for datamining applications. Pages 285-289 Proceedings of the sixth ACM SIGKDD international conference on Knowledge discovery and data mining. ACM Press, New Yok, NY.

Lee, S. J., K. J. Oh, and T. Y. Kim. 2012. How many reference patterns can improve profitability for real-time trading in futures market? Expert Systems with Applications 39:7458-7470.

Leonard, M., and B. Wolfe. 2001. Mining Transactional and Time Series Data Data Mining and Predictive Modeling. Data Mining and Predictive Modeling:1-26. Award Lecture. Ecology 73:1943-1967. 
Limburg, K. E., M. J. Wuenschel, K. Hüssy, Y. Heimbrand, and M. Samson. 2018. Making the

Mueen, A., and E. Keogh. 2016. Extracting Optimal Performance from Dynamic Time Warping. Pages 2129-2130 Proceedings of the 22nd ACM SIGKDD International Conference on

Myers, C. S., and L. R. Rabiner. 1981. A Comparative Study of Several Dynamic Time Warping Knowledge Discovery and Data Mining - KDD '16. ACM Press, New York, New York, USA.

Ortiz, J. J. G., C. P. Phoo, and J. Wiens. 2016. Heart Sound Classification Based on Temporal

Pi-Yun Chen, Neng-Sheng Pai, Guan-Yu Chen, and Hua-Jui Kuang. 2015. Design and implementation of a speech controlled omnidirectional robot using a DTW-based recognition algorithm. Page 279 in Teen-Hang Meen, Stephen D. Prior, and Arte Donald Kin-Tak Lam, editors. Applied System Innovation: Proceedings of the 2015 International Conference on Applied Systems Innovation. First edition. CRC Press - Taylor \& Francis, Osaka, Japan.

Rakthanmanon, T., B. Campana, A. Mueen, G. Batista, B. Westover, Q. Zhu, J. Zakaria, and E. Keogh. 2012. Searching and mining trillions of time series subsequences under dynamic time warping. Page 262 Proceedings of the 18th ACM SIGKDD international conference on Knowledge discovery and data mining - KDD ’12. ACM Press, New York, New York, USA.

Ratanamahatana, C., and E. Keogh. 2004. Everything you know about dynamic time warping is wrong. Pages 22-25 Third Workshop on Mining Temporal and Sequential Data.

Sakoe, H., and S. Chiba. 1978. Dynamic Programming Algorithm Optimization for Spoken Word Recognition. IEEE Transactions on Acoustics, Speech, and Signal Processing 26:43-

31 Sakurai, Y., Y. Matsubara, and C. Faloutsos. 2015. Mining and Forecasting of Big Time-series 
Salvador, S., and P. Chan. 2007. FastDTW : Toward Accurate Dynamic Time Warping in Linear

Sarda-Espinosa, A. 2017. Comparing Time-Series Clustering Algorithms in R Using the dtwclust Package.

Secor, D. H. 2010. Is otolith science transformative? New views on fish migration.

Scrucca, L., M. Fop, T. B. Murphy, and A. E. Raftery. 2016. mclust 5: Clustering, Classification and Density Estimation Using Gaussian Finite Mixture Models. The R Journal 8:289-317. Environmental Biology of Fishes 89:209-220.

Secor, D. H., J. M. Dean, and E. H. Laban. 1992. Otolith removal and preparation for microstructural analysis. Pages 19-57 in S. E. Campana and D. K. Stevenson, editors. Otolith Microstructure Examination and Analysis. Canadian S. Ottawa.

Stathopoulos, V., V. Zamora-Gutiérrez, K. E. Jones, and M. Girolami. 2014. Bat Call

Identication with Gaussian Process Multinomial Probit Regression and a Dynamic Time Warping Kernel. 17th International Conference on Artificial Intelligence and Statistics (AISTATS, JMLR: W\&CP 33:913-921.

Tan, L. N., A. Alwan, G. Kossan, M. L. Cody, and C. E. Taylor. 2015. Dynamic time warping and sparse representation classification for birdsong phrase classification using limited training dataa). The Journal of the Acoustical Society of America 137:1069-1080.

Tiffan, K. F., and W. P. Connor. 2012. Seasonal use of shallow water habitat in the Lower Snake River reservoirs by juvenile fall Chinook salmon. Walla Walla District, Walla Walla, WA. Tormene, P., T. Giorgino, S. Quaglini, and M. Stefanelli. 2009. Matching incomplete time series with dynamic time warping: an algorithm and an application to post-stroke rehabilitation. Artificial Intelligence in Medicine 45:11-34.

Ueno, K., A. Xi, E. Keogh, and D. J. Lee. 2006. Anytime classification using the nearest neighbor algorithm with applications to stream mining. Pages 623-632 Proceedings - IEEE International Conference on Data Mining, ICDM.

Walther, B. D. 2019. The art of otolith chemistry: Interpreting patterns by integrating perspectives. Marine and Freshwater Research 70:1643-1658.

Walther, B. D., and K. E. Limburg. 2012. The use of otolith chemistry to characterize 
diadromous migrations. Journal of Fish Biology 81:796-825.

2 Wang, G. J., C. Xie, F. Han, and B. Sun. 2012. Similarity measure and topology evolution of foreign exchange markets using dynamic time warping method: Evidence from minimal spanning tree. Physica A: Statistical Mechanics and its Applications 391:4136-4146.

Waples, R. S., A. Elz, B. D. Arnsberg, J. R. Faulkner, J. J. Hard, E. Timmins-Schiffman, and L. K. Park. 2017. Human-mediated evolution in a threatened species? Juvenile life-history changes in Snake River salmon. Evolutionary Applications.

Weideman, H. J., Z. M. Jablons, J. Holmberg, K. Flynn, J. Calambokidis, R. B. Tyson, J. B. Allen, R. S. Wells, K. Hupman, K. Urian, and C. V. Stewart. 2017. Integral Curvature

Williams, J. G., R. W. Zabel, R. S. Waples, J. A. Hutchings, and W. P. Connor. 2008. Potential for anthropogenic disturbances to influence evolutionary change in the life history of a threatened salmonid. Evolutionary Applications 1:271-285.

Wolkovich, E. M., B. I. Cook, K. K. McLauchlan, and T. J. Davies. 2014. Temporal ecology in

17 Xu, D., X. Wu, Y.-L. Chen, and Y. Xu. 2014. Online Dynamic Gesture Recognition for Human Robot Interaction. Journal of Intelligent and Robotic Systems: Theory and Applications 77:583-596. 